\title{
Neutrophil Migration and Adhesion Molecule Expression after Acute High-Intensity Street Dance Exercise
}

\author{
Leandro Borges $\mathbb{D}^{1},{ }^{1}$ Alexandre Dermargos, ${ }^{2}$ Stuart Gray, ${ }^{3}$ Maysa B. Barros Silva, ${ }^{1}$ \\ Vinicius Santos, ${ }^{1}$ Tania Cristina Pithon-Curi, ${ }^{1}$ Renata Gorjão, ${ }^{1}$ and Elaine Hatanaka ${ }^{1}{ }^{1}$ \\ ${ }^{1}$ Institute of Physical Activity and Sport Science (ICAFE), Cruzeiro do Sul University, São Paulo, SP, Brazil \\ ${ }^{2}$ Universidade Paulista (UNIP), São Paulo, SP, Brazil \\ ${ }^{3}$ Institute of Cardiovascular \& Medical Sciences, University of Glasgow, Glasgow, UK
}

Correspondence should be addressed to Leandro Borges; sbleandro@yahoo.com.br

Received 23 February 2018; Revised 20 April 2018; Accepted 6 June 2018; Published 8 July 2018

Academic Editor: Jacek Tabarkiewicz

Copyright ( 2018 Leandro Borges et al. This is an open access article distributed under the Creative Commons Attribution License, which permits unrestricted use, distribution, and reproduction in any medium, provided the original work is properly cited.

\begin{abstract}
The physical demands of street dancing may result in inflammation and changes in leukocyte numbers/function, impairing the health of dancers. Herein, we investigated the effect of street dancing on inflammation, adhesion molecules, and neutrophil function. Fifteen amateur dancers (mean \pm SE: age $22.4 \pm 1.08$ years, BMI $24.8 \pm 0.69 \mathrm{~kg} / \mathrm{m}^{2}$, and body fat $12.3 \pm 1.52 \%$ ) participated in a single high-intensity street dance class. Blood samples were taken before and after the class. The dance class had no effect on the plasma concentration of CRP, TNF- $\alpha$, IL-6, IL-10, and IL-8; however, we noted an increase in levels of IL-1 $\beta(4.06 \%)$ and sL-selectin (17.67\%). The dance class resulted in a $12.36 \%$ increase in neutrophil counts, while neutrophil CD62L expression and migration were reduced $(25.27 \%$ and $78.92 \%$, resp.). After the dance class, neutrophil production of IL- 8 and TNF- $\alpha$ increased, respectively, by $59.75 \%$ and $49.23 \%$, in the control condition, and $43.55 \%$ and $32.22 \%$, after LPS stimulation. A single bout of street dancing induced inflammation and reduced neutrophil migration and adhesion molecule expression. These findings may contribute to a better understanding of the susceptibility to infection after acute dance exercise.
\end{abstract}

\section{Introduction}

Hip-hop dance, a term that encompasses many styles, including popping, breakdance, funk, house, krumping, voguing, and street dance [1], has grown in popularity with an increasing number of television shows and movies and attracted a great number of followers [2]. As with other such exercises, dancing improves motor control, attention, cognition, and physical fitness, but intense training frequently leads to acute and/or chronic injury $[3,4]$. Indeed, a temporary suppression of the immune system, inflammation, and muscle damage after an acute bout of intense/exhaustive exercise are common findings. Increasingly, dancers are recognized as elite athletes and the physical demands placed on choreography and heavy performance loads can result in muscle damage and inflammation [5].

Under normal conditions, after muscle damage is induced, the inflammatory response is initiated by the release of inflammatory mediators, such as proinflammatory cytokines (i.e., tumor necrosis factor- $\alpha$ (TNF- $\alpha$ ) and interleukin $1 \beta$ (IL-1 $\beta)$ ) into the injured tissue $[6,7]$. When these events occur in an uncontrolled manner, the ensuing systemic inflammation can alter neutrophil numbers and activation status, which may lead to increased susceptibility to invasive microorganisms and may negatively affect the dancers' performance and health. Sequentially, the soluble forms of sL-selectin and CD62L (bound to the membranes of leukocytes), as well as other adhesion molecules, initiate the emigration of leukocytes, by regulating the flux of rolling neutrophils and inflammatory monocytes [8], playing a critical role for the initiation of leukocyte responses [9].

In order to understand inflammatory modulation by neutrophils, studies have used treatment with lipopolysaccharide (LPS) stimulus to induce changes in Toll-like receptor 4 signaling pathways and NF-kappa B activation, simulating the exaggerated host response to infection through the release 
of cytokines and adhesion molecules [6]. Moreover, one of the first steps in infection control is the coordinated signaling that orchestrates the migration of neutrophils to the inflammatory site [10]. Herein, we investigated the effects of a single street dance class on markers of inflammation and immune function in dancers. Inflammation was monitored by plasma cytokines (TNF- $\alpha$, interleukin-6 (IL-6), interleukin-10 (IL-10), and interleukin-8 (IL-8)) and C-reactive protein (CRP) measurement. We also assessed sL-selectin levels, neutrophil numbers, migration, expression of CD62L and IL-8, and TNF- $\alpha$ release by stimulated and nonstimulated neutrophils.

\section{Methods}

2.1. Subjects. With the approval of the Ethics Committee at the Cruzeiro do Sul University (0522013), 15 male dancers volunteered to participate in the study. All dancers signed an informed consent form agreeing to submit to the procedures involved in the study. The group had the following characteristics (mean \pm standard error (SE)): age $22.4 \pm 1.08$ years, weight $70.8 \pm 1.93 \mathrm{~kg}$, height $169 \pm 0.02 \mathrm{~cm}$, body mass index (BMI) $24.8 \pm 0.69 \mathrm{~kg} / \mathrm{m}^{2}$, fat-free mass $61.5 \pm 1.64 \mathrm{~kg}$, body fat $12.3 \pm 1.52 \%$, and dance experience of $7 \pm 13.78$ years. The dancers had a training/performance history of $3.7 \pm$ 0.39 hours a day, four days a week, and rested on weekends.

Participants were excluded from the study if they had a history of recent infection (last 15 days prior to the study), viruses, chronic lesions, diabetes, rheumatoid arthritis, hormonal dysfunction, lupus, or other inflammatory and hematology diseases (such as hemoglobinopathies) and took medication. To verify the dancer's health level, hematological parameters were assessed. The group presented the following characteristics (mean $\pm \mathrm{SE}$ ): red blood cells (RBC) $5.4 \pm 0.14 \times 10^{3} / \mathrm{mm}^{3}$, white blood cells (WBC) $9 \pm 0.53 \times 10^{3} / \mathrm{mm}^{3}$, hemoglobin ( $\left.\mathrm{Hb}\right) \quad 14.7 \pm 0.29 \mathrm{~g} / \mathrm{dL}$, hematocrit $(\mathrm{Ht}) 44.2 \pm 0.88 \%$, mean red cell volume $83 \pm$ $1.86 \mathrm{fL}$, and hemoglobin concentration per red blood cell (MCHC) $33.3 \pm 2.40 \%$.

2.2. Study Design and Blood Collection. For this study, dancers were asked to rest for 72 hours before the street dance class. During the class, all participants had their heart rate (HR) monitored using Polar HR monitors and danced for 60 minutes at high intensity. This was defined according to the following intensities via HR reserve: at $85 \pm 5.9 \%$ in the first 20 minutes, at $88.9 \pm 3.9 \%$ between 20 and 40 minutes, and at $89.2 \pm 3.3 \%$ between 40 and 60 minutes of the class.

Twenty milliliters $(\mathrm{mL})$ of venous blood was collected before and immediately after the street dance class. Blood samples were drawn into BD Vacutainer ${ }^{\circledR}$ tubes, containing heparin. After collecting the samples, blood was centrifuged at $400 \times \mathrm{g}$ for 10 minutes and the plasma was used to evaluate cytokines and CRP. Moreover, neutrophils were isolated from whole blood for cellular analyzes.

2.3. CRP and Cytokine Measurements. Plasma CRP and cytokines (TNF- $\alpha$, IL-6, IL-10, IL-8, sL-selectin, and IL-1 $\beta$ ) were measured by ELISA, according to the manufacturer's instructions (DuoSet Kit: Quantikine, R\&D System, Minneapolis, MN, USA). A standard curve was produced for each set of samples, and the cytokine was assayed [11].

2.4. Isolation of Neutrophils. Cell isolation was carried out within 1 hour of venipuncture [12]. Human neutrophils were extracted from whole blood under endotoxin-free state using Histopaque $^{\circledR}-1077$ (Sigma Chemical Co., St. Louis, MO) following to the supplier's instructions and previously described by Böyum [13].

2.5. Cell Culture. After isolation, the cultured cell concentration obtained was $87.6 \times 10^{6}$. Neutrophils $\left(2.5 \times 10^{6}\right)$ were suspended in Roswell Park Memorial Institute (RPMI) 1640 medium supplemented with $0.3 \mathrm{~g} / \mathrm{L}$ glutamine, $2.32 \mathrm{~g} / \mathrm{L}$ Hepes, $2 \mathrm{~g} / \mathrm{L}$ sodium bicarbonate, $100 \mu \mathrm{g} / \mathrm{mL}$ streptomycin, $100 \mathrm{UI} / \mathrm{mL}$ penicillin, and $10 \%$ fetal bovine serum. The cells were then counted in a Neubauer chamber and immediately cultured at $37^{\circ} \mathrm{C}$ and $5 \% \mathrm{CO}_{2}$, with and without LPS $(5 \mu \mathrm{g} / \mathrm{mL})$ supplied by Sigma Chemical Co. (St. Louis, $\mathrm{MO})$. After 18 hours of cell culture, the supernatant was collected and stored at $\leq-80^{\circ} \mathrm{C}$ prior to cytokine analysis (IL- 8 and TNF- $\alpha$ ) by ELISA (Quantikine, R\&D System, Minneapolis, MN, USA).

2.6. Expression of CD62L. The expression of CD62L (BD Biosciences, NJ, USA) was measured with a FACSAria II flow cytometer (Becton Dickinson, San Juan, CA, USA) from neutrophils $\left(2.5 \times 10^{6}\right.$ cells $\left./ \mathrm{mL}\right)$. In summary, the MEL-14 monoclonal antibody is conjugated with the fluorochrome fluorescein isothiocyanate (FITC) and recognizes an epitope localized to the lectin domain and CD62L binds a number of fucosylated, glycosylated, sulfated sialylated glycoproteins including CD34, MAdCam-1, and glycam-1. Data were acquired and analyzed using Diva software (Becton Dickinson), and results were expressed as the mean of the FITC fluorescence intensity. Ten thousand events were analyzed per experiment.

2.7. Neutrophil Chemotaxis. Neutrophil chemotactic responses were measured using 96-well disposable chemotactic plates (Neuro Probe), according to the manufacturer's instructions. Briefly, flat-bottomed chambers were filled with the chemotactic agent N-formyl-methionyl-leucyl-phenylalanine (fMLP) (Sigma Chemical, St. Louis, MO) $(10 \mathrm{nmol} / \mathrm{L})$ in phosphate-buffered saline (PBS) containing $0.01 \%$ albumin. Chemotactic membranes with a pore size of $5 \mu \mathrm{m}$ were fixed to the filter seat. The chamber assembly with neutrophils $\left(2.5 \times 10^{4}\right.$ cells $\left./ \mathrm{mL}\right)$ was incubated in a humidified $5 \%$ $\mathrm{CO}_{2}$ atmosphere at $37^{\circ} \mathrm{C}$ for 60 minutes. After incubation, the chamber was disassembled and the cells that migrated, crossing the plasma membrane, were counted directly in the Neubauer chamber and chemotactic responses were defined as the mean number of migrated neutrophils. The chemotactic factor fMLP $(10 \mathrm{nmol} / \mathrm{L})$ was used as a positive control for migration. Results were normalized to the number of cells that transmigrated under control conditions (PBS without fMLP). 
TABLE 1: Effect of participation in a street dance class on plasma CRP, IL- $1 \beta$, TNF- $\alpha$, IL-6, IL-10, and IL- 8 in terms of picograms per milliliter $(\mathrm{pg} / \mathrm{mL})$. Values were determined before and immediately after the class and are presented as the means \pm SE for 9-13 dancers. ${ }^{*} p<0.005$ (compared with the before-class condition).

\begin{tabular}{lcc}
\hline & Pre & Post \\
\hline CRP $(\mathrm{pg} / \mathrm{mL})$ & $1157.63 \pm 49.51$ & $1037.11 \pm 73.03$ \\
IL-1 $\beta(\mathrm{pg} / \mathrm{mL})$ & $8.04 \pm 0.08$ & $8.38 \pm 0.11^{*}$ \\
TNF- $\alpha(\mathrm{pg} / \mathrm{mL})$ & $481.82 \pm 118.03$ & $469.07 \pm 104.79$ \\
IL-6 $(\mathrm{pg} / \mathrm{mL})$ & $26.73 \pm 6.55$ & $26.37 \pm 5.23$ \\
IL-10 $(\mathrm{pg} / \mathrm{mL})$ & $73.63 \pm 0.59$ & $74.17 \pm 0.75$ \\
IL-8 $(\mathrm{pg} / \mathrm{mL})$ & $25.27 \pm 0.33$ & $25.43 \pm 0.44$ \\
\hline
\end{tabular}

2.8. Statistical Analysis. The results are expressed as the means \pm SE. Statistical analysis of plasma cytokines and CRP, neutrophil counts, cell migration, and CD62L expression data was performed by paired $t$-test. Analysis of cytokine production by neutrophils (IL- 8 and TNF- $\alpha$ ) was performed using a one-way analysis of variance (ANOVA) accompanied by post hoc test (Student-Newman-Keuls multiple comparison) (InStat; GraphPad Software, San Diego, CA, USA). Significance was accepted at $p<0.05$. Linear relationships were explored by Pearson's correlation.

\section{Results}

Table 1 shows the plasma concentration of CRP and cytokines before and immediately after a street dance class. Although we did not find differences in the plasma concentration of CRP, TNF- $\alpha$, IL-6, IL-10, and IL- 8 (Table 1), the street dance class resulted in an increase in plasma IL- $1 \beta$ levels $(4.06 \%, p<0.005)$ (Table 1$)$.

As shown in Figure 1, the street dance class resulted in an increase in total neutrophil count $(12.36 \%, p<0.05)$ and in the concentration of sL-selectin $(17.67 \%, p<0.05)$ (Figures 1(a) and 1(b), resp.). On the other hand, the street dance class resulted in a reduction in neutrophil CD62L $(25.27 \%, p<0.01)$ and neutrophil migration $(78.92 \%$, $p<0.05$ ) (Figures 1(c) and 1(d), resp.).

LPS stimulation resulted in an increase in neutrophil production of IL-8 (41.95\% (baseline) and 18.59 (post), $p<0.05$ ) and TNF- $\alpha$ (45.9\% (baseline) and 27.77 (post), $p<0.05$ ) (Figures 2(a) and 2(b), resp.). Moreover, neutrophil production of IL-8 (Figure 2(a)) and TNF- $\alpha$ (Figure 2(b)) increased by $59.75 \%(p<0.01)$ and $49.23 \%(p<0.01)$, respectively, in the basal condition, and by $43.55 \% \quad(p<0.05)$ and $32.22 \%(p<0.05)$, respectively, in LPS-stimulated conditions, after the street dance class.

Figure 3 shows a positive correlation between plasma sL-selectin concentration and the intensity of dancing performed, measured via HR reserve $\left(r^{2}=0.60, p<0.0001\right)$ (Figure 3(a)), and a negative correlation between the neutrophil expression of CD62L and the intensity of dancing $\left(r^{2}=-0.64, p<0.05\right)$ (Figure 3(b)).

\section{Discussion}

Our results demonstrated that a single session of street dancing, lasting 60 minutes, increased the concentration of IL- $1 \beta$ and sL-selectin, indicating the induction of inflammation. sL-selectin, from neutrophils, is found in the plasma at high levels, and it may retain functional activity, indicating a possible role for sL-selectin in the regulation of leukocyte attachment to endothelium [14]. sL-selectin also plays an important role in the migration of lymphocytes into peripheral lymph nodes and sites of chronic inflammation and in the migration of neutrophils to acute inflammatory sites [8]. Interestingly, our results showed a positive correlation between sL-selectin and dance intensity. Since selectins have been reported to promote the subsequent activation of immune cells, playing a critical role for the initiation of leukocyte responses [9], our data indicate that increasing dance intensity could result in greater inflammation and increases in plasma soluble adhesion molecules.

After the class, neutrophil count increased but the expression of CD62L on neutrophils was lower. In addition, we found that neutrophil productions of IL- 8 and TNF- $\alpha$ in the control and LPS-stimulated conditions were increased and there was a reduction in neutrophil migration immediately after the dance class. In contrast to our data, some investigations have reported increased neutrophil chemotactic activity after moderate exercise $[15,16]$. However, the intensity, type and duration of exercise can influence leukocyte immune responses $[17,18]$, and it should be noted that the dance class in this study was performed at an intensity of $85-90 \%$ of the HR reserve, which represents a high-intensity activity. Moreover, the mechanism for the decreased chemotactic activity in athletes may be related to humoral factors which influence chemotaxis or may imply exercise-induced intrinsic alterations in the cell itself [19]. In order to investigate further impaired chemotaxis after submaximal aerobic exercise, Gavrieli et al. [20] studied adult males before and 24 hours after 30 minutes of treadmill running at $75 \%$ of maximal oxygen uptake $\left(\mathrm{VO}_{2}\right.$ max). Similar to our data, they found that neutrophil chemotaxis was impaired after exercise [20]. They suggested that the pathophysiological mechanism of impaired migration is likely associated with impaired postexercise neutrophil adherence [20], a hypothesis supported by previous studies that have demonstrated that submaximal exercise reduces leukocyte adherence in active men $[21,22]$.

Although the clinical significance of the transient reduction in neutrophil chemotaxis after intense exercise, such as street dance, is still not clear, it is important to keep in mind that neutrophil function is a key component in the resolution of infection and the control of inflammation [8]. Once in the lung parenchyma, for example, neutrophils release antimicrobial factors and phagocytose bacteria that reduce the action of pathogens. Nevertheless, these mediators can also deteriorate host tissue if the neutrophil-mediated inflammatory response is not properly controlled, resulting in an elevated susceptibility to respiratory infections [23]. Thus, it is likely that the reduction in neutrophil chemotaxis and increased inflammation status of dancers reflects an "open 


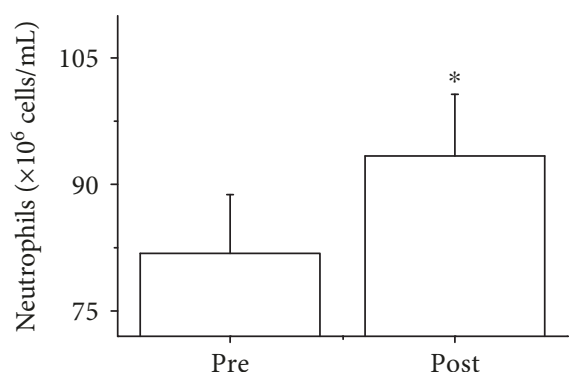

(a)

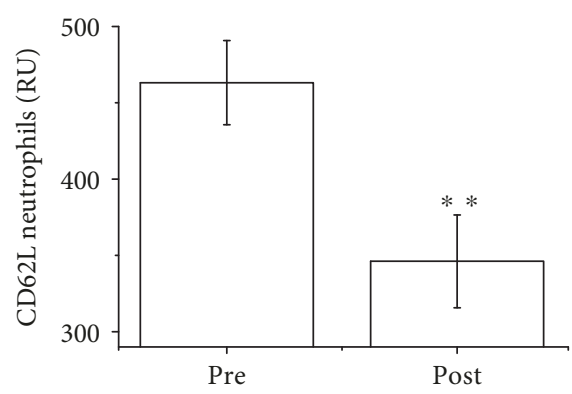

(c)

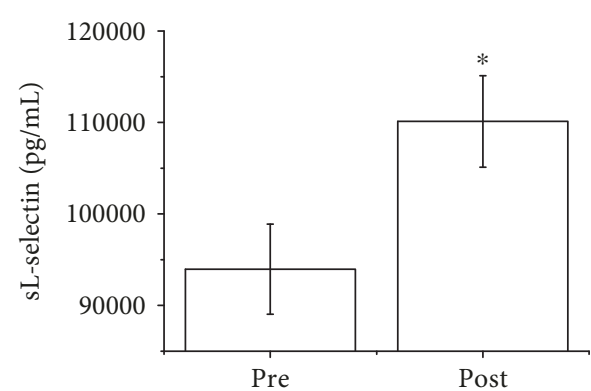

(b)

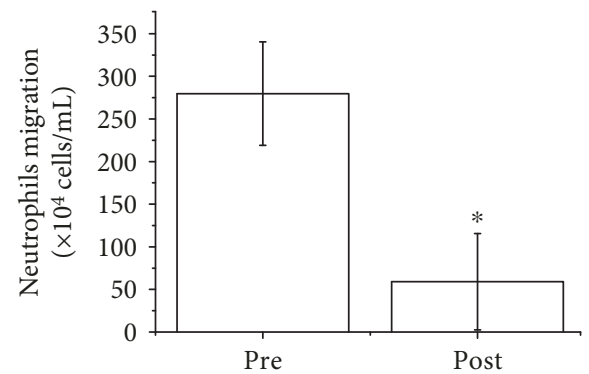

(d)

FIGURE 1: Total count of neutrophils $\left(\times 10^{6}\right.$ cells $\left./ \mathrm{mL}\right)(\mathrm{a})$, plasma sL-selectin (pg/mL) (b), CD62L expression (relative units (RU)) (c), and migration $\left(\times 10^{6}\right.$ cells $\left./ \mathrm{mL}\right)(\mathrm{d})$ of neutrophils determined before and immediately after the street dance class. The values are presented as the mean \pm SE for $10-14$ dancers. ${ }^{*} p<0.05$ and ${ }^{* *} p<0.01$ (compared with the before-class condition).

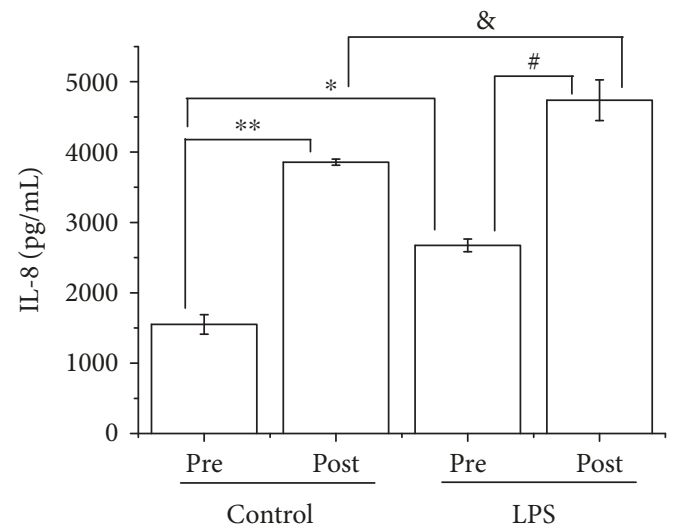

(a)

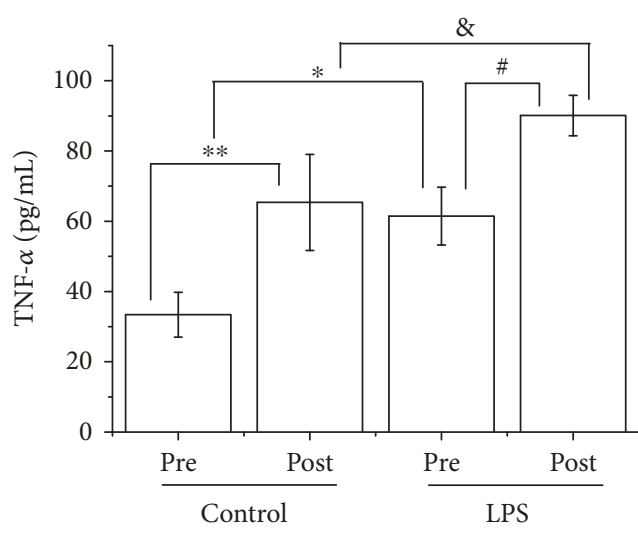

(b)

Figure 2: IL-8 (pg/mL) (a) and TNF- $\alpha(\mathrm{pg} / \mathrm{mL})$ (b) release by neutrophils before and immediately after a street dance class. The measurements were taken in the control and LPS-stimulated conditions. The values are presented as mean \pm SE of $9-14$ players. ${ }^{*} p<0.05$ compared with the before-class condition (no LPS); ${ }^{* *} p<0.01$ compared with the before-class condition (no LPS); ${ }^{\#} p<0.05$ compared with the before-class condition (LPS); ${ }^{\circledR} p<0.05$ compared with the postclass condition (no LPS).

window" in which host defense is reduced and the risk of infection is elevated [17]. It is also important to mention that, prior to this study, research on street dance and inflammation has been primarily descriptive or restricted to case studies and further long-term studies are needed to confirm whether street dancers do have higher infection prevalence/incidence.

In fact, short-term, high-intensity exercise can lead to a significant and prolonged dysfunction of the peripheral blood leukocytes, which is accompanied by an increase in proinflammatory mediators. To illustrate this, Tuan et al.
[24] investigated 12 healthy volunteers for 3 consecutive days of high-intensity exercise training $\left(85 \%\right.$ of $\mathrm{VO}_{2}$ max for 30 minutes every day). Plasma concentrations of TNF- $\alpha$ and soluble Fas ligand were raised during the exercise sessions and had not returned to normal 72 hours after the completion of exercise [24]. This supports the potentially deleterious effects of excessive exercise on immune function and health [18].

The current study found that neutrophil numbers increased immediately following a street dance class. However, the expression of CD62L by neutrophils was reduced by the class. We observed a negative correlation between 


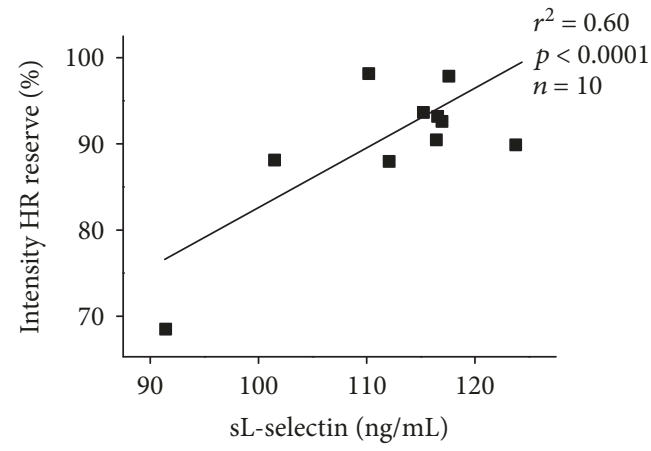

(a)

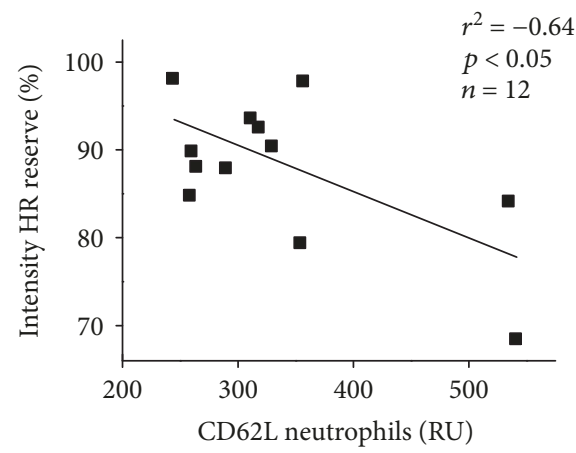

(b)

FIgURE 3: The degree of linear relationship between exercise intensity and sL-selectin plasma levels $\left(r^{2}=0.60, p<0.0001\right)$ (a) and with the expression of CD62L by neutrophils $\left(r^{2}=-0.64, p<0.05\right)$ (b) was established by Pearson's correlation. Levels of sL-selectin and expression of CD62L were quantified before and immediately after the street dance class. Values refer to absolute post values and are presented as the means \pm SE for 8-12 dancers in terms of nanograms per milliliter (ng/mL) and RU, respectively. ${ }^{*} p<0.01$ compared with the before-class condition.

exercise intensity and expression of CD62L, indicating that effect of exercise on the expression of adhesion molecules, an important event for the rolling, adhesion, and migration of neutrophils [9], is intensity dependent. Previous studies have already demonstrated the role of CD62L adhesion molecules in the transmigration of leukocytes, performing critical points of the immune role of host defense [25].

As expected, the neutrophil production of IL-8 and TNF- $\alpha$ was higher with LPS stimulation. An important aspect of neutrophil function is their ability to modulate the inflammatory response via the systemic production of cytokines, such as TNF- $\alpha$ and other inflammatory mediators [26]. These leukocytes have a high phagocytic capacity and, when a pathogen is engulfed, releases IL-8, which recruits further neutrophils to the site of infection [27]. Moreover, the street dance class increased the basal responsiveness of neutrophils, increasing the release of TNF- $\alpha$ and IL- 8 in the nonstimulated (absence of stimuli) and stimulated conditions. This increased production of cytokines by neutrophils after the dance class points to dancing as a priming agent for subclinical inflammation.

The serum concentrations of TNF- $\alpha$, IL- $1 \beta$, and IL- 8 are associated with the severity of inflammatory processes [6]. Also, the plasma increase in IL-1 $\beta$ in the current study agrees with the current literature, as other studies have shown that intense exercise [7], and even some dance modalities [4], induces muscle injury and, as a consequence, leads to increase in proinflammatory markers $[10,28]$. Moreover, Keller et al. [29] demonstrated a marked increase in plasma levels of some cytokines not seen in our study, such as IL-6 [29]; however, local tissue IL-6 elevation is noted mostly during shorter exercise, whereas systemic IL-6 increases are usually observed only with longer exercise $[30,31]$. The current exercise protocol had a short time duration (60 minutes), and even if there was a local tissue increase of IL-6, this was not evident in the systemic circulation. Thus, studies that target local tissue levels of cytokines related to the effect of dance could represent a promising path in future research.
Intensive exercise suppresses several leukocyte functions including chemotaxis and the release of cytokines by leukocytes [32]. The findings of this study support the concept that intense street dance classes may adversely affect the immune system, demonstrating the potential for street dance to negatively modify neutrophil function which will potentially increase the risk of infectious diseases in amateur dancers. Future studies are necessary to assess the risk of infection in dancers over the long term.

\section{Conclusion}

An acute bout of street dancing induces inflammation and reduces neutrophil migration and adhesion molecule expression. These findings improve our understanding of the risk of infection following acute dance exercise, and it may represent a useful tool to design new studies and strategies to prevent a dancer's performance from declining as a result of inflammation/infection.

\section{Data Availability}

Data arising from this study are contained within the manuscript.

\section{Conflicts of Interest}

The authors declare that there is no conflict of interest regarding the publication of this article.

\section{Acknowledgments}

The authors are indebted to Thaís Reis Martins for her technical assistance. The authors also thank the volunteers for providing the samples used in this work. This work was supported by the Brazilian research funding agencies FAPESP (São Paulo Research Foundation) (Grant nos. 2011/21441-0 and 2014/21185-1) and the CNPq (National 
Council for Scientific and Technological Development) (Grant no. 306041/2011-1).

\section{References}

[1] S. Bronner, S. Ojofeitimi, and H. Woo, "Extreme kinematics in selected hip hop dance sequences," Medical Problems of Performing Artists, vol. 30, no. 3, pp. 126-134, 2015.

[2] M. Rajakumar, Hip Hop Dance, ABC-CLIO, Santa Barbara, CA, USA, 2012.

[3] C. Miller, "Dance medicine: current concepts," Physical Medicine and Rehabilitation Clinics of North America, vol. 17, no. 4, pp. 803-811, 2006.

[4] L. da Silva Borges, J. R. Bortolon, V. C. Santos et al., "Chronic inflammation and neutrophil activation as possible causes of joint diseases in ballet dancers," Mediators of Inflammation, vol. 2014, Article ID 846021, 7 pages, 2014.

[5] S. Bronner, S. Ojofeitimi, and D. Rose, "Injuries in a modern dance company: effect of comprehensive management on injury incidence and time loss," The American Journal of Sports Medicine, vol. 31, no. 3, pp. 365-373, 2003.

[6] I. Striz, E. Brabcova, L. Kolesar, and A. Sekerkova, "Cytokine networking of innate immunity cells: a potential target of therapy," Clinical Science, vol. 126, no. 9, pp. 593-612, 2014.

[7] N. R. de Moura, L. S. Borges, V. C. Santos et al., "Muscle lesions and inflammation in futsal players according to their tactical positions," Journal of Strength and Conditioning Research, vol. 27, no. 9, pp. 2612-2618, 2013.

[8] S. Y. Tan and W. Weninger, "Neutrophil migration in inflammation: intercellular signal relay and crosstalk," Current Opinion in Immunology, vol. 44, pp. 34-42, 2017.

[9] A. Zarbock, K. Ley, R. P. McEver, and A. Hidalgo, "Leukocyte ligands for endothelial selectins: specialized glycoconjugates that mediate rolling and signaling under flow," Blood, vol. 118, no. 26, pp. 6743-6751, 2011.

[10] N. P. Walsh, M. Gleeson, R. J. Shephard et al., "Position statement. Part one: immune function and exercise," Exercise Immunology Review, vol. 17, pp. 6-63, 2011.

[11] M. G. S. Amorim, M. D. de Oliveira, D. S. Soares, L. da Silva Borges, A. Dermargos, and E. Hatanaka, "Effects of exergaming on cardiovascular risk factors and adipokine levels in women," The Journal of Physiological Sciences, 2017.

[12] P. B. Noble, J. H. Cutts, and K. K. Carroll, "Ficoll flotation for the separation of blood leukocyte types," Blood, vol. 31, no. 1, pp. 66-73, 1968.

[13] A. Böyum, "Isolation of leucocytes from human blood. Further observations. Methylcellulose, dextran, and ficoll as erythrocyteaggregating agents," Scandinavian Journal of Clinical and Laboratory Investigation Supplementum, vol. 97, pp. 31-50, 1968.

[14] B. Schleiffenbaum, O. Spertini, and T. F. Tedder, "Soluble L-selectin is present in human plasma at high levels and retains functional activity," The Journal of Cell Biology, vol. 119, no. 1, pp. 229-238, 1992.

[15] E. Ortega, M. E. Collazos, M. Maynar, C. Barriga, and M. de la Fuente, "Stimulation of the phagocytic function of neutrophils in sedentary men after acute moderate exercise," European Journal of Applied Physiology and Occupational Physiology, vol. 66, no. 1, pp. 60-64, 1993.

[16] G. D. Syu, H. I. Chen, and C. J. Jen, "Differential effects of acute and chronic exercise on human neutrophil functions,"
Medicine and Science in Sports and Exercise, vol. 44, no. 6, pp. 1021-1027, 2012.

[17] J. M. Peake, O. Neubauer, N. P. Walsh, and R. J. Simpson, "Recovery of the immune system after exercise," Journal of Applied Physiology, vol. 122, no. 5, pp. 1077-1087, 2017.

[18] J. M. Peake, K. Suzuki, M. Hordern, G. Wilson, K. Nosaka, and J. S. Coombes, "Plasma cytokine changes in relation to exercise intensity and muscle damage," European Journal of Applied Physiology, vol. 95, no. 5-6, pp. 514-521, 2005.

[19] E. Ortega, "Neuroendocrine mediators in the modulation of phagocytosis by exercise: physiological implications," Exercise Immunology Review, vol. 9, pp. 70-93, 2003.

[20] R. Gavrieli, T. Ashlagi-Amiri, A. Eliakim et al., "The effect of aerobic exercise on neutrophil functions," Medicine and Science in Sports and Exercise, vol. 40, no. 9, pp. 1623-1628, 2008.

[21] P. J. Mills, S. Hong, L. Redwine et al., "Physical fitness attenuates leukocyte-endothelial adhesion in response to acute exercise," Journal of Applied Physiology, vol. 101, no. 3, pp. 785-788, 2006.

[22] R. J. Shephard, "Adhesion molecules, catecholamines and leucocyte redistribution during and following exercise," Sports Medicine, vol. 33, no. 4, pp. 261-284, 2003.

[23] K. Hoenderdos and A. Condliffe, "The neutrophil in chronic obstructive pulmonary disease," American Journal of Respiratory Cell and Molecular Biology, vol. 48, no. 5, pp. 531-539, 2013.

[24] T. C. Tuan, T. G. Hsu, M. C. Fong et al., "Deleterious effects of short-term, high-intensity exercise on immune function: evidence from leucocyte mitochondrial alterations and apoptosis," British Journal of Sports Medicine, vol. 42, no. 1, pp. 11-15, 2008.

[25] S. D. Kobayashi, J. M. Voyich, K. R. Braughton, and F. R. DeLeo, "Down-regulation of proinflammatory capacity during apoptosis in human polymorphonuclear leukocytes," Journal of Immunology, vol. 170, no. 6, pp. 3357-3368, 2003.

[26] A. Mantovani, M. A. Cassatella, C. Costantini, and S. Jaillon, "Neutrophils in the activation and regulation of innate and adaptive immunity," Nature Reviews Immunology, vol. 11, no. 8, pp. 519-531, 2011.

[27] K. L. Rock, J. J. Lai, and H. Kono, "Innate and adaptive immune responses to cell death," Immunological Reviews, vol. 243, no. 1, pp. 191-205, 2011.

[28] N. R. de Moura, M. F. Cury-Boaventura, V. C. Santos et al., "Inflammatory response and neutrophil functions in players after a futsal match," Journal of Strength and Conditioning Research, vol. 26, no. 9, pp. 2507-2514, 2012.

[29] P. Keller, C. Keller, A. L. Carey et al., "Interleukin-6 production by contracting human skeletal muscle: autocrine regulation by IL-6," Biochemical and Biophysical Research Communications, vol. 310, no. 2, pp. 550-554, 2003.

[30] G. Mastorakos and I. Ilias, "Interleukin-6: a cytokine and/or a major modulator of the response to somatic stress," Annals of the New York Academy of Sciences, vol. 1088, no. 1, pp. 373381, 2006.

[31] E. Z. Fisman and A. Tenenbaum, "The ubiquitous interleukin6: a time for reappraisal," Cardiovascular Diabetology, vol. 9, no. 1, p. 62, 2010.

[32] M. W. Kakanis, J. Peake, E. W. Brenu et al., "The open window of susceptibility to infection after acute exercise in healthy young male elite athletes," Exercise Immunology Review, vol. 16, pp. 119-137, 2010. 


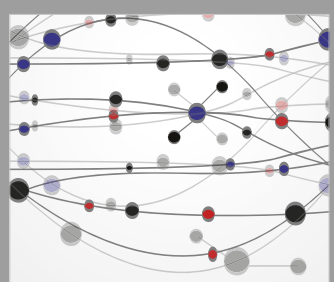

The Scientific World Journal
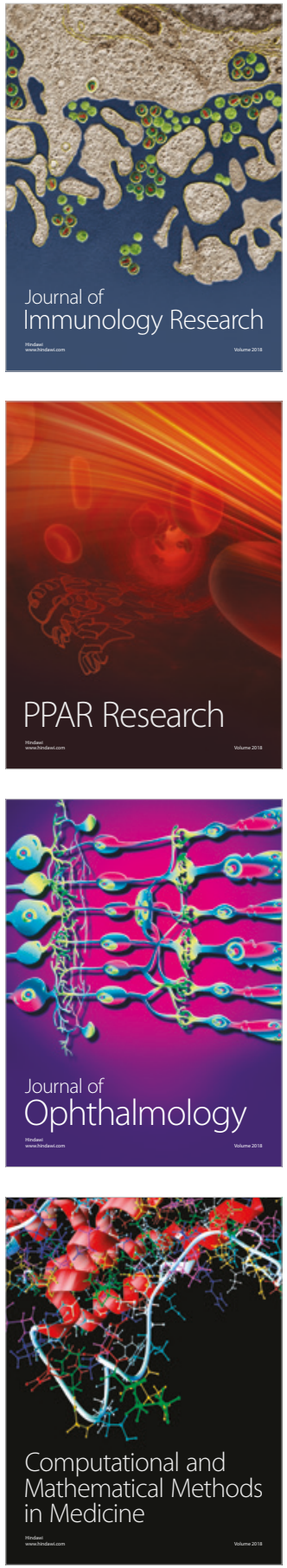

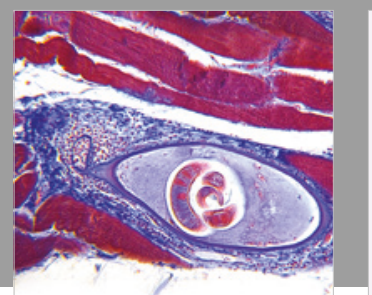

Gastroenterology Research and Practice

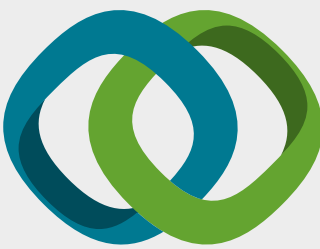

\section{Hindawi}

Submit your manuscripts at

www.hindawi.com
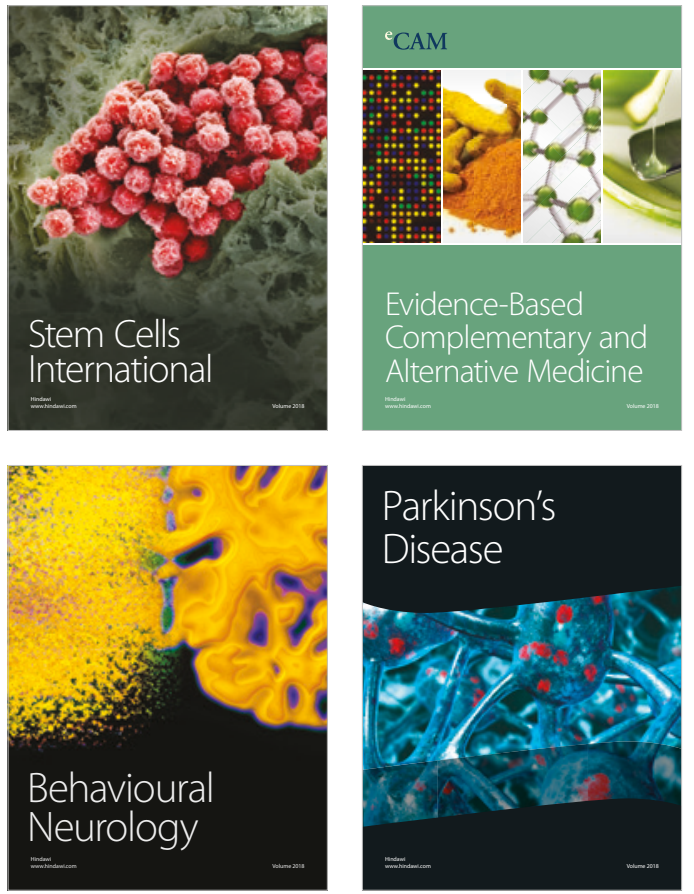

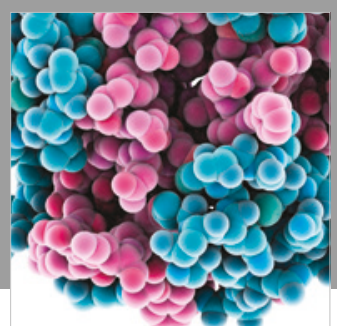

ournal of

Diabetes Research

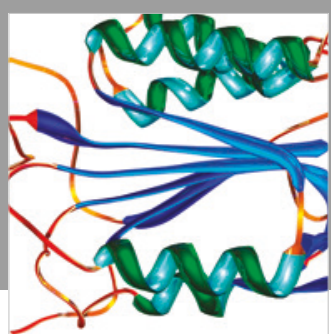

Disease Markers
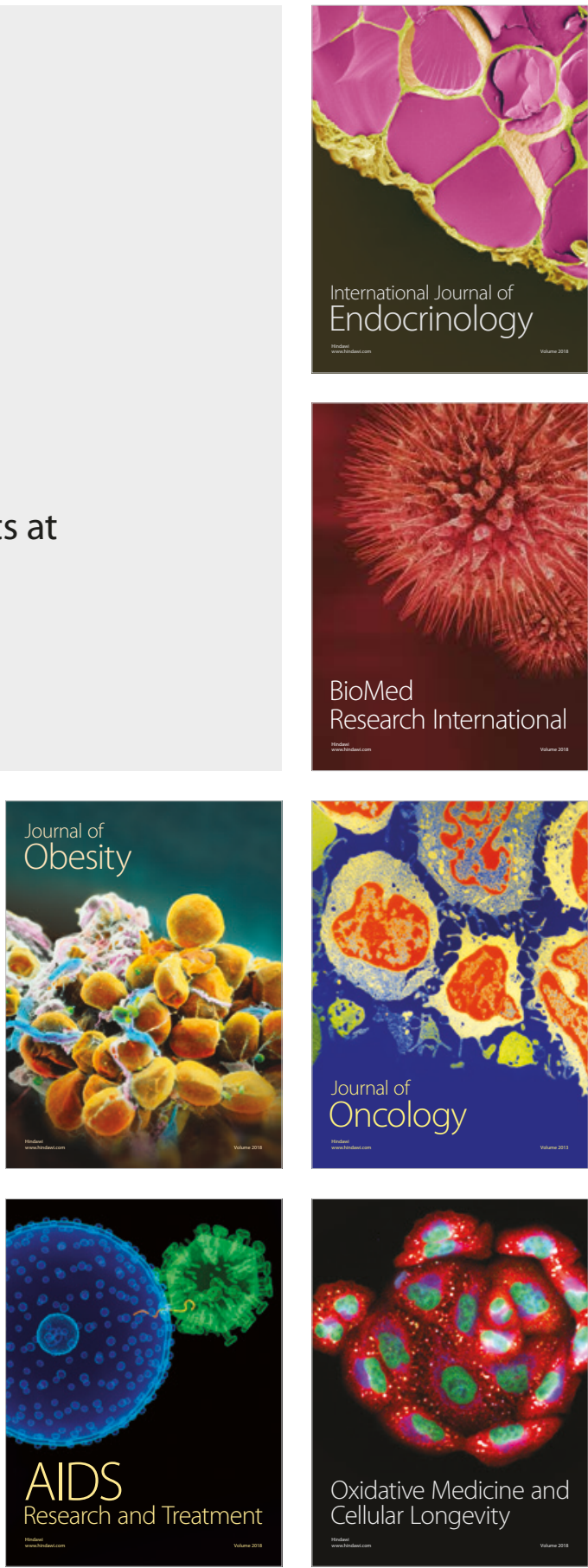